\title{
Europa - falsch verstanden
}

Gustav A. Horn

Die Erleichterung war groß. Endlich hat der Europäische Ministerrat Mitte März Entscheidungen über die institutionellen Reformen getroffen, die den Euroraum langfristig gegen Krisen schützen sollen. So schält sich allmählich eine erneuerte Struktur des Währungsraums heraus, mit der die einzelnen Mitgliedsländer in den kommenden Jahren werden leben müssen.

Das, was sich nun neu bildet, kann aber noch nicht das letzte Wort gewesen sein. Dazu enthält das Gesamtkonzept noch zu viele Fehler. Vor allem aber skizzieren die Vorschläge eine Reform gegen die Arbeitnehmer, die das Gros der Anpassungslast im Krisenfall zu tragen hätten.

Dabei ist der Beschluss, einen permanenten Rettungsschirm für den Euroraum einzurichten, im Prinzip völlig richtig. Auf diese Weise wird die Unsicherheit über die künftigen Stützungsmöglichkeiten auch für die derzeitigen Krisenländer beseitigt. Allein das hätte die Märkte schon beruhigen und zu verminderten Risikoaufschlägen führen sollen. Aber die Reaktion der Märkte zeigt, dass dem nicht so ist. Und das liegt daran, dass der Zins, den der Rettungsschirm den Schuldnerländern für die Unterstützungszahlungen abverlangt, trotz Senkung im Falle Griechenlands immer noch zu hoch ist, um einen glaubwürdigen Entschuldungsprozess zu ermöglichen. Damit bleibt die Verunsicherung der Märkte letztlich bestehen.

Neben dem Rettungsschirm wurde aber auch ein Pakt für den Euro, vormals in seiner deutsch-französischen Fassung auch Pakt für Wettbewerbsfähigkeit genannt, geschlossen. Dessen Ziel ist es, die Wettbewerbsfähigkeit aller Mitgliedsländer des Euroraums zu steigern. Dieser Pakt, der gegenüber seiner Ursprungsfassung noch merklich abgeschwächt worden ist, ist freilich ein erschreckendes Dokument einer falschen Diagnose.

Zunächst einmal ist festzuhalten, dass der Euroraum als Ganzes überhaupt keine Wettbewerbsprobleme hat. Denn seine Leistungsbilanz mit dem Rest der Welt ist mehr oder minder ausgeglichen. Allerdings haben einzelne Länder im Euroraum, nämlich jene, die seit Jahren eine hoch defizitäre Leistungsbilanz aufweisen, sehr wohl Wettbewerbsprobleme. Für diese Länder, und das sind die Krisenländer Griechenland, Irland, Spanien und Portugal, ist es erforderlich, ihre Wettbewerbsfähigkeit zu verbessern. Aber sollen die gleichen Maßnahmen auch für solche Länder wie Deutschland gelten, die angesichts hoher Leistungsbilanzüberschüsse offenkundig keinerlei Wettbewerbsprobleme aufweisen? Dies würde die Maßnahmen zur Steigerung der Wettbewerbsfähigkeit in Ländern wie Griechenland sogar konterkarieren, denn Wettbewerbsfähigkeit ist ein relatives Konzept und kein absolutes. Man ist immer nur in Relation zu einer oder mehreren anderen Volkswirtschaften wettbewerbsfähig, aber nie losgelöst vom Rest der Welt.

Ein weitaus größeres Problem besteht darin, wie die Anpassungslast bei Leistungsbilanzungleichgewichten festgelegt wird:
Sie wird allein der Lohnbildung aufgebürdet. In den Defizitländern soll durch Lohnzurückhaltung Wettbewerbsfähigkeit erzeugt werden, was im Grundsatz richtig ist. In symmetrischer Argumentation müssten jedoch in den Überschussländern höhere Lohnsteigerungen für eine stärkere Binnennachfrage sorgen, mit deren Hilfe die Leistungsbilanzungleichgewichte abgebaut werden könnten. Dies wäre eine Win-Win-Strategie für den Euroraum. Die Krisenländer bekämen die Chance, sich aus eigener Kraft aus der Krise zu befreien, zudem wäre der Anpassungsdruck bei den Löhnen dort entsprechend geringer. In den Überschussländern könnten Abschreibungen von Auslandsvermögen in und Transfers an Krisenländer vermieden werden. Gleichzeitig würde der Wohlstand in der Bevölkerung durch spürbar höhere Löhne gesteigert werden. Die Sorge, dass damit ein Verlust an Exporten einhergeht, ist unbegründet, so lange sich die Lohnsteigerungen nicht allzu weit über den Rahmen der Produktivitätsentwicklung und der Preisstabilität hinausbewegen. Zwar kommt es im Vergleich zu den Krisenländern zu Verlusten von Marktanteilen, aber diese werden durch die höhere wirtschaftliche Dynamik, die durch die Überwindung der Krise ausgelöst wird, mehr als kompensiert. Eine symmetrische Lohnreaktion ist also kein Nullsummenspiel, sondern nützt allen. Umso befremdlicher ist das Fehlen dieser Symmetrie im Rahmen des Paktes für den Euro. Hier werden Chancen verschenkt, insbesondere zulasten der Arbeitnehmer. Den griechischen Arbeitnehmern wird eine ungeheure Last aufgebürdet, und die deutschen werden an den Früchten der Exporterfolge nicht hinreichend beteiligt.

Kein Thema ist hingegen für den Euro-Pakt die Gewinninflation. Sie hat z.B. in Spanien mit der spekulativen Blasenbildung im Immobiliensektor, in der sich auch die Exporterfolge der deutschen Wirtschaft widerspiegeln, maßgeblich zu der überhöhten Inflationsrate beigetragen. Gewinne sind in der vom angebotspolitischen Denken geprägten Wirtschaftpolitik ein Tabu. Gänzlich in Schieflage geraten die Vorstellungen der Regierungen, wenn sie die Löhne des öffentlichen Sektors zu einem Instrument der Herstellung von Wettbewerbsfähigkeit degradieren. Damit wird der Staat nicht mehr als Arbeitgeber gesehen, der sich in freien Lohnverhandlungen mit den Forderungen seiner Beschäftigten auseinandersetzen muss, sondern als Exekutor eines europäischen Lohndiktats.

Dies alles verdichtet sich zu dem düsteren Bild eines Euroraums, dessen Architektur gegen die Interessen der Arbeitnehmer gerichtet ist. Das aber kann nicht das gewünschte Europa sein.

Gustav A. Horn, Prof. Dr., ist wissenschaftlicher Direktor des Instituts für Makroökonomie und Konjunkturforschung (IMK) in der Hans-Böckler-Stiftung. e-mail: gustav-horn@boeckler.de 